Emre Akyuz

Metin Celik

http://dx.doi.org/10.21278/brod68104

ISSN 0007-215X

eISSN 1845-5859

\title{
USING OF A'WOT TO DESIGN AN ENHANCED PLANNED MAINTENANCE SYSTEM (E-PMS) ON-BOARD SHIP
}

UDC 629.5.083.4:629.5.07

Original scientific paper

\begin{abstract}
Summary
Repair and maintenance is a critical technical aspect on board ship. Poor maintenance planning may lead to serious impairment in safety, efficiency, and environmental performance since researches show that a significant breakdowns and damage to ships with maintenance system. This study investigates the potential of existing planned maintenance system (PMS), mainly adopted strategy on board ships, to point out the required improvements. The PMS is a comprehensive periodic maintenance system for equipment or machinery. It is formulated by the ship management company or ship owner associated with requirements of manufacturer and ship classification society. An A'WOT hybrid methodology is utilized to quantify the strengths, weakness, opportunities and threats of PMS. To develop an e-PMS concept, the proposed solutions are decided respectively. The e-PMS concept enables a considerable amount of contributions to ship system performance and reliability once it integrates into safety management system.
\end{abstract}

Key words: Ship management, maintenance, planned maintenance system, AHP and SWOT analysis

\section{Introduction}

The main philosophy on technical system and engineering design identifies a distinct link among the elementary design characteristics and technical system properties. Hubka and Eder [1] argue that managing the design considerations with the manufacturing and ergonomic properties, economic issues, functional and operational properties such as operational safety, maintainability, reliability, operating costs, are critical parameters to be able to ensure economic lifecycle and service period of overall system or performance of its components in desired levels. Among the design considerations, maintainability characteristics and maintenance facilitates are significant phenomena in terms of managing design and operation process of complex technical systems in an efficient manner [2-6].

The maintenance planning procedure on-board ships is so complicated and it requires great effort due to a large numbers of limitations on the process such as time and personnel limitation [7-8], safety aspects [9], international maritime regulations, environmental risks, 
emergency conditions, and catastrophes [10] when compare with shore-based maintenances such as manufacturing factories, petroleum platforms, electric power plants, refineries, etc. According to the Chapter 10 of ISM (International Safety Management) Code, each shipping company should develop the maintenance planning which is capable of offering a systematic approach including inspections, corrective actions, testing of equipments, etc [11-12]. Therefore, selecting the most appropriate maintenance system and executing the most effective maintenance strategies are very critical issue to ensure reliable, safely, and efficient shipboard operations. In this paper, the A'WOT technique is adopted to design enhanced planned maintenance system (e-PMS) on-board ship. The PMS is a comprehensive periodic maintenance system for equipment or machinery established by the ship management company. This paper aims to identify and establish a priority ranking of the main factors that affecting the current PMS on-board ship and design the e-PMS concept by integrating the other maintenance strategies. So that, proposed approach is capable of overcoming the limitation of the current PMS and providing an enhancement throughout strategic maintenance planning on-board ship.

Within this scope, the paper is organized as follows; the main philosophy of maintenance system and technical information about the maintenance procedures on-board ships is introduced in Section 1. Section 2 focuses on literature review on maintenance planning. Section 3 expresses the proposed methodology. The model demonstration is provided in section 4 . The final section gives conclusion and future research prospect.

\section{Literature review on maintenance planning}

Since the different types of industries have various operational principles and structural characteristics, adopting an appropriate maintenance system requires elaborative systematic approaches. For shipboard systems, the pressures of the operational constraints, safety-related expectations, and environmental concerns in global perspective increase the complexity of the problem. Although studies for planned maintenance system on off-shore and maritime systems are limited in the literature, a wide range of research papers are proposed in different fields such as manufacturing, chemical plants, power plants, nuclear systems, etc. In this context, Wang et al. evaluated different maintenance strategies in power plant systems component by using Fuzzy Analytic Hierarchy Process (FAHP) as Multiple Criteria DecisionMaking (MCDM) method under fuzzy environments [13]. On the other hand, Bevilacqua and Braglia proposed traditional AHP (Analytic Hierarchy Process) methodology in order to select the best maintenance strategy for an oil refinery processing plant [14]. Another paper was introduced by Mechefske and Wang [15]. In the paper, a fuzzy linguistic approach adopted to achieve the subjective assessments of maintenance strategies and managing practices. Furthermore, Labib developed a different systematic model under fuzzy environment for aiding the computerized maintenance management systems (CMMSs) in execution process [16]. Additionally, Pintelon et al. developed a framework to identify and evaluate the effectiveness of maintenance strategy [17]. Another study was performed by Zeng who performed a sensitive analysis through robotic car assembly lines to introduce optimum maintenance strategy [18]. On the other hand, a detailed investigation was conducted by Waeyenbergh and Pintelon [19]. In the research, the authors overview benefits and shortfalls each maintenance strategy.

The decision-making models under fuzzy environment provide additional contributions to identify the popular maintenance strategies. For instance, Almeida and Bohoris introduced a multi-attribute utility theory in maintenance [20]. Furthermore, a hybrid decision-making approach was developed by integrating AHP technique into Goal Programming (GP) for maintenance selection problem [21]. 
The literature review has clearly indicated that the current approaches through maintenance strategy based on decision-making method whereas the problem requires an additional support by strategy-making tools. Therefore, the SWOT analysis is integrated to enhance the current planned maintenance system for shipboard operation.

On the other hand, the researches show that the studies on maintenance strategies in maritime industry (merchant ships, off-shore systems, oil platforms or port and terminals) are very limited in the literature. For instance, a reliability-centred maintenance in maritime operations was discussed by Mokashia et al. [22]. Furthermore, an integrated maintenance management system based on fuzzy information axioms was proposed by Cebi et al. for shipboard systems [2]. Thus, an effective maintenance management system is introduced for ship owners and ship management companies.

\section{Methodology}

This paper introduces a model-based approach which is integrating SWOT and AHP techniques in order to design e-PMS concept. The quantification process of the SWOT analysis is achieved by the AHP. This is called A'WOT (hybrid multi-criteria decision making method). The next section introduces both methods and briefly describes how the methods are combined.

\subsection{SWOT technique}

The SWOT (Strengths, Weaknesses, Opportunities and Threats) is commonly applied planning tool to evaluate the strengths, weaknesses, opportunities and threats of a project or a business venture. The method allows user to analyse internal conditions and external environments to promote a systematic approach and to support strategy decisions [23-24]. The internal and external factors are considered as strategic factors. Accordingly, they are grouped into four categories which can be briefly expressed as follows;

- Strength implies the competitive advantages over the others,

- Weakness refers to absence of certain strengths,

- Opportunity implies new opportunities for advantages and growth,

- Threat refers to elements that may cause problems,

In order to evaluate strategies for alternative maintenance, a strategy-making tool is required. Therefore, application of the SWOT analysis along with integrated decision-making method is introduced. Despite applications of traditional SWOT analysis in numerous disciplines [25-27], the new trends have been shifted into hybrid decision-making approaches to manage strategy. In this paper, the SWOT analysis is used to determine strengths, weaknesses, opportunities and threats of internal/external factors for the PMS.

\subsection{AHP}

The AHP technique, introduced by Saaty, is a common used tool for comparing a number of alternatives with respect to an overall goal in a consistent manner [28]. The model is quite useful to obtain relevant attributes prioritized in a hierarchic structure [29-30]. The method is capable of dividing complex problem into small parts, rank them hierarchically, compare elements with a pair-wise matrix, evaluate the relative importance and determine ranking of decision alternatives [31].

In the first step, a pair-wise comparison matrix (A) is established by using a pair-wise comparison scale [28]. Saaty's 1-9 scale is illustrated in Table 1. 
Table 1 Saaty's pair-wise comparison scale.

\begin{tabular}{ll}
\hline Importance & Definition \\
\hline 1 & Equal importance \\
3 & Moderate importance \\
5 & Strong importance \\
7 & Very strong importance \\
9 & Absolute extreme) importance \\
$2,4,6,8$ & Intermediate values \\
\hline
\end{tabular}

As provided in the matrix $A$, each criterion $a_{i j}(i, j=1,2,3, \ldots, n)$ is the relative importance of $\mathrm{i}^{\text {th }}$ elements when compared to the $\mathrm{j}^{\text {th }}$ elements. Basically, it depicts that higher value of $a_{i j}$ shows stronger preference of the criteria $a_{i}$ against $a_{j}$. In matrix $A, a_{i j}=1$ when $i=j$ and and $a_{j i}=1 / a_{i j}$.

$$
A=\left[\begin{array}{cccc}
1 & a_{12} & \cdots & a_{1 n} \\
a_{21} & 1 & \cdots & a_{2 n} \\
\vdots & \vdots & \ddots & \vdots \\
a_{n 1} & a_{n 2} & \cdots & 1
\end{array}\right] \quad a_{i i}=1, a_{j i}=1 / a_{i j}, a_{i j} \neq 0
$$

In the second step, the priority weights of each criterion $\left(w_{1}, w_{2}, \ldots ., w_{j}\right)$ will be calculated by using following equation.

$$
w_{i}=\frac{1}{n} \sum_{j=1}^{n} \frac{a_{i j}}{\sum_{k=1}^{n} a_{k j}}
$$

In the final step, consistency of data is examined. As provided in equation (3), a consistency index (CI) can be calculated.

$$
C I=\frac{\lambda_{\max }-n}{n-1}
$$

In the above equation, $n$ is the order of the matrix, and $\lambda_{\max }$. is maximum eigenvalue of the matrix and it can be calculated by using following formula [32-33].

$$
\sum_{j=1}^{n} \alpha_{i j} w_{j}=\lambda_{\max } w_{i}
$$

Thereafter, the consistency ratio (CR) is calculated (Eq.5). If the CR value is equal or less than 0.1, the judgments inserted in a pair-wise comparison matrix are considered as consistent and reasonable.

$$
C R=C I / R I
$$

In the equation, RI denotes Random Index and introduced by Saaty. 
Table 2 Random index value.

\begin{tabular}{lllllllllll}
\hline$n$ & 1 & 2 & 3 & 4 & 5 & 6 & 7 & 8 & 9 & 10 \\
$\boldsymbol{R I}$ & $\boldsymbol{0}$ & $\boldsymbol{0}$ & $\mathbf{0 . 5 8}$ & $\mathbf{0 . 9 0}$ & $\mathbf{1 . 1 2}$ & $\mathbf{1 . . 2 4}$ & $\mathbf{1 . 3 2}$ & $\mathbf{1 . 4 1}$ & $\mathbf{1 . 4 5}$ & $\mathbf{1 . 4 9}$ \\
\hline
\end{tabular}

\subsection{Hybrid methodology: A'WOT maintenance}

The SWOT technique provides the basic framework for strategic planning while the AHP technique enables to capture each SWOT group weight. The combination of the SWOT and AHP method is called A'WOT and introduced by Kurttila et al. [35]. The proposed approach enhances the quantitative basis for shipboard maintenance system and brings analytic solutions for the SWOT factors. The outcomes of quantitative SWOT analysis provide contributions to decision-makers and strategists. Hence, the A'WOT systematically identifies relationships between the threats, opportunities, weaknesses and strengths. In the literature, the A'WOT method is applied to a wide range of disciplines such as design \& construction projects [36], forest planning [37], environmental management [38], tourism management [39], agricultural management [40], and port management [41].

In this paper, the proposed model-A'WOT is employed to design e-PMS concept onboard ship. A flow diagram of the proposed approach is depicted in Figure 1. The method is applied into five main steps. The first step is to determine internal and external SWOT factors. The second step is composing a pair-wise comparison matrix. The next step utilizes the prioritization of the SWOT factors. In step four, the CR is calculated. Then, the final step designs the e-PMS concept to overcome limitations of the current PMS. 


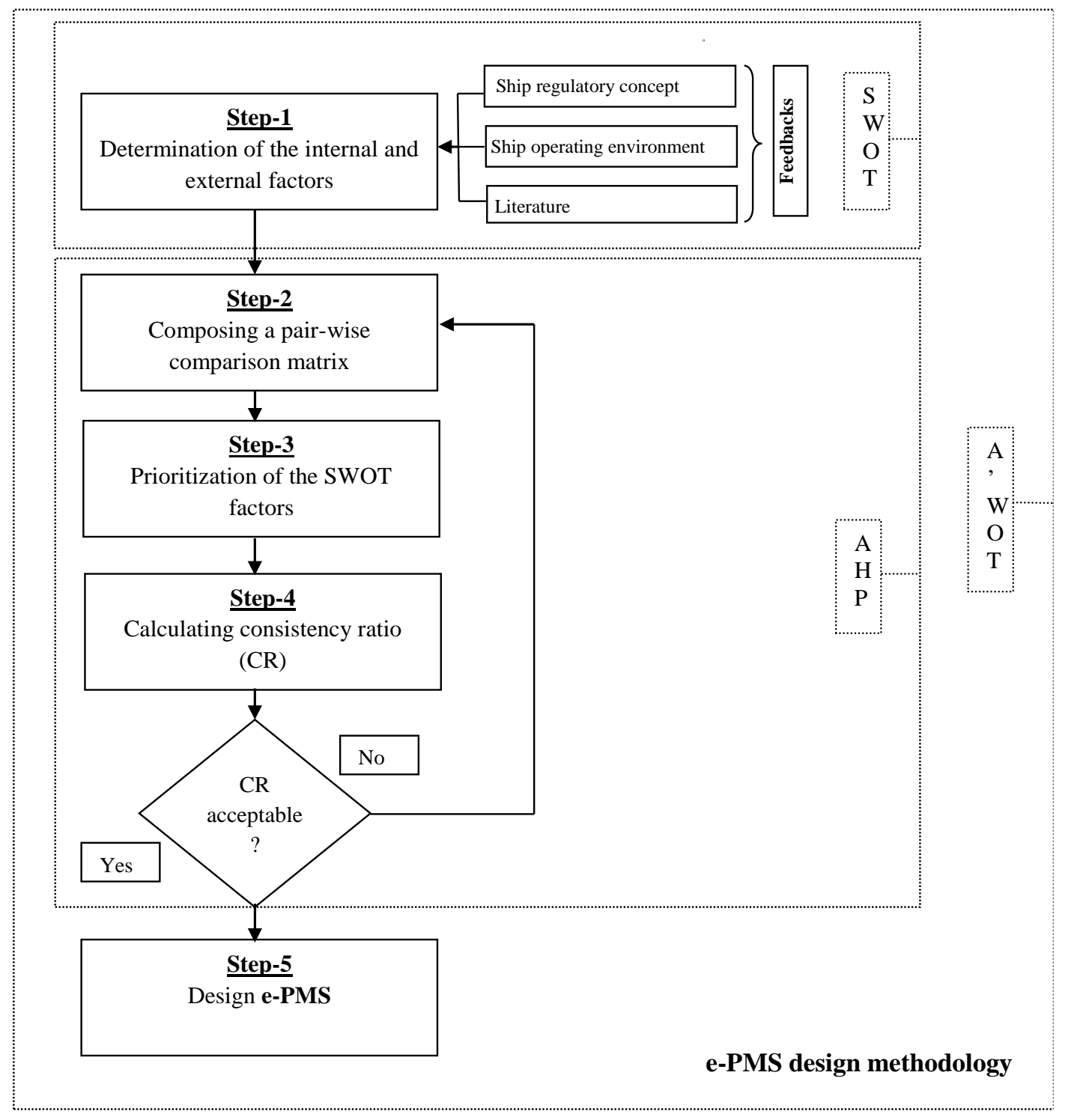

Fig. 1 A flow diagram of methodology.

\section{Design e-PMS concept}

The proposed approach is used to design the e-PMS for shipboard maintenance system. To achieve this purpose, a set of surveys were conducted. A prestigious shipping company which has a chemical tanker fleet was visited. The surveys were conducted with marine experts (superintendents) who worked at ship for a long years as a chief engineer. The surveys consist of questions with respect to comparison of the criteria. At the end of the survey, a confidential data set is derived.

\subsection{Maintenance system requirements on-board ships}

Effectiveness of the ship maintenance system depends on critical parameters such as reliability, endurance, failure probability interval, physical life, etc. In a broad sense, this process can be achieved by selecting appropriate maintenance systems such as total productive maintenance, planned maintenance, preventive maintenance, reactive maintenance, predictive maintenance and reliability-centred maintenance. In operational level, the most 
appropriate maintenance method is adopted to maintain performance of technical systems, plants, and complex infrastructures. On the other hand, a comprehensive maintenance system is required due to complexity of shipboard systems. According to the ISM Code, an available maintenance systems on-board ship should be established to ensure that the vessel is maintained in conformance with international maritime rules and regulations. The ISM Code also requires maintenance system which must identify equipments and technical systems that may cause sudden operational failure. In order to fulfil aforementioned requirements the maintenance system must include regular testing, continuous recording of stand-by equipment and technical systems [42]. Therefore, the e-PMS concept is proposed to enhance maintenance systems by improving the performance of shipboard operations. To accomplish this, alternative strategies to the machinery components/equipment is adopted. Thus, the optimal balance is provided for shipboard maintenance. In order to design e-PMS concept, the current PMS must be analysed in terms of the A'WOT. In particular, the weaknesses and threats of the current PMS are revealed. Thereafter, alternative solutions should be integrated into the current PMS to deal with the weaknesses and threats.

\subsection{PMS for shipboard operation}

The PMS is a kind of tool which allows ship management companies or ship owners to carry out regular maintenance in accordance with manufacturer or classification society requirements. The maintenance shall be conducted by the ship crew and supervised by the ship owner and ship regulatory authorities such as the classification society or flag state. Moreover, the PMS is applicable to a wide range of operations on-board ship such as main engine, auxiliary engines, boiler, ballast and cargo pumps, separator system, pollution prevention equipments, steering gear system, firefighting system, cargo handling equipments, cargo holds, deck machinery, etc. Furthermore, the planning and scheduling of the maintenance shall be compliance with related maritime regulations. The purpose of the PMS is briefly [43];

- Ensuring that all maintenance is conducted at appropriate intervals,

- Providing that all maintenance is carried out in accordance with the schedule,

- Avoiding interruption of work,

- Maintaining all systems such as engines, machineries or equipments,

- Providing link among ship and shore maintenance work.

\subsection{Determination of internal and external factors of PMS}

In order to design e-PMS concept, the SWOT analysis is used to identify internal and external factors affecting the planned maintenance system. These are extracted from ship regulatory concept, ship operating environment and literature. The findings may assist to identify internal and external factors of the PMS. In this context, since technical and operational factors are considered as internal, administrative \& managerial factors are considered as external. The factors are distributed into four groups; strengths, weaknesses, opportunities and threats on the basis of SWOT analysis which are provided in Table 3 respectively. 
Table 3 SWOT analysis of PMS.

Strength

Provide flexibility in work scheduling

Cost effective and timely procurement of spare parts

Enable to increase component life cycle

Enable continuous monitoring of system and equipment conditions

Reduce probability of delay in manoeuvring and voyage

Record relevance activities systematically

\section{Weakness}

Not responding to sudden operational failure

Includes performance of unnecessary maintenance

Potential for hazardous damage to components in

conducting unnecessary maintenance

Possible to be applied all ships in the form of copies due to absence of system subjectivity

Have a significant start up time since PMS works with software
Code

$S_{1}$

$S_{2}$

$S_{3}$

$S_{4}$

$S_{5}$

$S_{6}$

$W_{1}$

$W_{2}$

$W_{3}$

$W_{4}$

$W_{5}$

$\mathrm{O}_{1}$

$\mathrm{O}_{2}$

$\mathrm{O}_{3}$

$\mathrm{O}_{4}$

$\mathrm{O}_{5}$

O6

Capable of managing labour work controlling and distribution properly

\section{Threats}

Need well trained crew

$T_{1}$

Able to lead crew for uniform

$T_{2}$

Require continuous updates due to regulation changing $\quad T_{3}$

Encourage to crew effortlessness $T_{4}$

To make difficult to check whether the work is done or not in practice $\quad T_{5}$

\subsection{Composing a pair-wise comparison matrix}

After performed the SWOT analysis, a pair-wise comparison matrix for SWOT group is composed by using Saaty's 1-9 scale. The survey data, received from marine experts (superintendents), is converted to numerical data. Since group opinion is considered in the decision-making process, the survey results are reduced to one comparison matrix by using geometric means of judgements. In this paper, the aggregation of individual judgments has been performed right after data acquisition since individual identities are lost with every stage of aggregation and a synthesis of the hierarchy produces the group's priorities [44, 45]. Accordingly, the SWOT groups are compared by using equation (1). Each marine expert is asked to describe the relative importance of each factor in accordance with a relative importance scale. Table 4 provides comparison of the SWOT groups accordingly.

Table 4 Comparison of SWOT group. 


\begin{tabular}{lcccc}
\hline & $\begin{array}{c}\text { Strengths } \\
(S)\end{array}$ & $\begin{array}{c}\text { Weaknesses } \\
(W)\end{array}$ & $\begin{array}{c}\text { Opportunities } \\
(O)\end{array}$ & $\begin{array}{c}\text { Threats } \\
(T)\end{array}$ \\
\hline Strengths $(S)$ & 1 & 4 & 2 & 5 \\
Weaknesses $(W)$ & $1 / 4$ & 1 & $1 / 3$ & 2 \\
Opportunities $(O)$ & $1 / 2$ & 3 & 1 & 4 \\
Threats $(T)$ & $1 / 5$ & $1 / 2$ & $1 / 4$ & 1 \\
\hline
\end{tabular}

Likewise, factors of each SWOT group are compared in accordance with equation (1). Table 5, 6, 7 and 8 illustrate the comparison matrix of the each SWOT factor respectively.

Table 5 Comparison of strength factor.

\begin{tabular}{lcccccc}
\hline & $S_{1}$ & $S_{2}$ & $S_{3}$ & $S_{4}$ & $S_{5}$ & $S_{6}$ \\
\hline$S_{1}$ & 1 & $1 / 3$ & $1 / 4$ & $1 / 3$ & $1 / 4$ & $1 / 3$ \\
$S_{2}$ & 3 & 1 & 2 & 3 & $1 / 2$ & 3 \\
$S_{3}$ & 4 & $1 / 2$ & 1 & 3 & $1 / 3$ & $1 / 4$ \\
$S_{4}$ & 3 & $1 / 3$ & $1 / 3$ & 1 & $1 / 4$ & 1 \\
$S_{5}$ & 4 & 2 & 3 & 4 & 1 & 4 \\
$S_{6}$ & 3 & $1 / 3$ & 4 & 1 & $1 / 4$ & 1 \\
\hline
\end{tabular}

Table 6 Comparison of weakness factor.

\begin{tabular}{lccccc}
\hline & $W_{1}$ & $W_{2}$ & $W_{3}$ & $W_{4}$ & $W_{5}$ \\
\hline$W_{1}$ & 1 & 4 & 2 & 6 & 3 \\
$W_{2}$ & $1 / 4$ & 1 & $1 / 2$ & $1 / 3$ & $1 / 2$ \\
$W_{3}$ & $1 / 2$ & 2 & 1 & 3 & 2 \\
$W_{4}$ & $1 / 6$ & 3 & $1 / 3$ & 1 & $1 / 3$ \\
$W_{5}$ & $1 / 3$ & 2 & $1 / 2$ & 3 & 1 \\
\hline
\end{tabular}

Table 7 Comparis on of opportunity factor.

\begin{tabular}{lcccccc}
\hline & $\mathrm{O}_{1}$ & $\mathrm{O}_{2}$ & $\mathrm{O}_{3}$ & $\mathrm{O}_{4}$ & $\mathrm{O}_{5}$ & $O_{6}$ \\
\hline $\mathrm{O}_{1}$ & 1 & $1 / 3$ & $1 / 4$ & $1 / 3$ & $1 / 5$ & 1 \\
$\mathrm{O}_{2}$ & 3 & 1 & $1 / 3$ & 2 & $1 / 3$ & $1 / 2$ \\
$\mathrm{O}_{3}$ & 4 & 3 & 1 & 3 & $1 / 2$ & 2 \\
$\mathrm{O}_{4}$ & 3 & $1 / 2$ & $1 / 3$ & 1 & $1 / 3$ & $1 / 3$ \\
$O_{5}$ & 5 & 3 & 2 & 3 & 1 & 3 \\
$O_{6}$ & 1 & 2 & $1 / 2$ & 3 & $1 / 3$ & 1 \\
\hline
\end{tabular}

Table 8 Comparison of threat factor.

\begin{tabular}{lccccc}
\hline & $T_{1}$ & $T_{2}$ & $T_{3}$ & $T_{4}$ & $T_{5}$ \\
\hline$T_{1}$ & 1 & $1 / 4$ & 1 & $1 / 5$ & $1 / 3$ \\
$T_{2}$ & 4 & 1 & $1 / 2$ & $1 / 3$ & $1 / 4$ \\
$T_{3}$ & 1 & 2 & 1 & $1 / 3$ & $1 / 3$ \\
$T_{4}$ & 5 & 3 & 3 & 1 & 2 \\
$T_{5}$ & 3 & 4 & 3 & $1 / 2$ & 1 \\
\hline
\end{tabular}




\subsection{Prioritization of the SWOT factors}

The priority weights of the SWOT groups and sub-factors are calculated by using equation (2). Table 9 shows priority weight of SWOT factors.

\subsection{Calculating consistency ratio (CR)}

The consistency ratio (CR) of the matrixes can be calculated by using equations (3), (4) and (5). Table 9 provides the CR values for the SWOT groups and factors. All data inserted in the matrices is found consistent since the CR values are found equal or less than 0.10 .

\subsection{Findings}

The overall performance results are provided in Table 9 including internal and global priority weightings as well as internal and global rankings. According to the Table 9, the strength factor of the PMS is the most prominent since it has the highest priority weight (0.490) among the factors. It means that the current PMS is apparently the best appropriate maintenance system for shipboard operations. However, there are still some opportunities which may be evaluated since it has the second highest priority weight (0.305). Furthermore, there are weaknesses and threats that should be examined. As illustrated in the Table $9, \mathrm{~W}_{1}$ (Not responding to sudden operational failure), $\mathrm{W}_{3}$ (Potential for hazardous damage to components in conducting unnecessary maintenance) and $\mathrm{W}_{5}$ (Have a significant start up time since PMS works with software) are the three key aspects since they have the highest priority weight as major weaknesses. Meanwhile, from the point of view the threats group; $\mathrm{T}_{4}$ (Encourage to crew effortlessness), $T_{5}$ (To make difficult to check whether the work is done or not in practice) and $\mathrm{T}_{2}$ (Able to lead crew for uniform) are the three key factors with the highest priority that should be tackled. For example, $\mathrm{T}_{4}$ (Encourage to crew effortlessness) may lead to crew not to perform required job/task properly. Since PMS requires a set of tasks that are being completed in specific period, the crew may skip or perform careless job. Even, they do not carry out task in practice and fill in paper only. Another situation is $T_{2}$ (Able to lead crew for uniform) which may cause crew to carry out their job without thinking. The repetitive work, like an autopilot, may cause loss of concentration and cause not to see failure or unusual circumstance during maintenance period. The crew perform their job in a monotone and cannot distinguish in case unusual situation is occurred. The other factors, which are assessed in the weaknesses and threats group, obtained a low priority weight. 
Table 9 Overall assessment of the SWOT group and factors.

\begin{tabular}{|c|c|c|c|c|c|c|c|c|}
\hline SWOT group & $\begin{array}{l}\text { Priority } \\
\text { weight }\end{array}$ & Global rank & $\begin{array}{c}C R \\
\text { value }\end{array}$ & $\begin{array}{l}\text { SWOT } \\
\text { factors }\end{array}$ & $\begin{array}{c}\text { Internal } \\
\text { priority weight }\end{array}$ & $\begin{array}{l}\text { Internal } \\
\text { ranking }\end{array}$ & $\begin{array}{c}\text { Gloabal } \\
\text { priority weight }\end{array}$ & $\begin{array}{l}\text { Gloabal } \\
\text { ranking }\end{array}$ \\
\hline \multirow[t]{7}{*}{ Strenght } & 0.490 & 1 & 0.100 & & & & & \\
\hline & & & & $S_{1}$ & 0.052 & 6 & 0.025 & 12 \\
\hline & & & & $S_{2}$ & 0.221 & 2 & 0.108 & 2 \\
\hline & & & & $S_{3}$ & 0.138 & 4 & 0.068 & 5 \\
\hline & & & & $S_{4}$ & 0.092 & 5 & 0.045 & 6 \\
\hline & & & & $S_{5}$ & 0.346 & 1 & 0.170 & 1 \\
\hline & & & & $S_{6}$ & 0.150 & 3 & 0.074 & 4 \\
\hline \multirow[t]{6}{*}{ Weakness } & 0.126 & 3 & 0.081 & & & & & \\
\hline & & & & $W_{l}$ & 0.426 & 1 & 0.054 & 5 \\
\hline & & & & $W_{2}$ & 0.082 & 5 & 0.010 & 17 \\
\hline & & & & $W_{3}$ & 0.227 & 2 & 0.029 & 10 \\
\hline & & & & $W_{4}$ & 0.105 & 4 & 0.013 & 16 \\
\hline & & & & $W_{5}$ & 0.160 & 3 & 0.020 & 14 \\
\hline \multirow[t]{7}{*}{ Opportunity } & 0.305 & 2 & 0.100 & & & & & \\
\hline & & & & $O_{1}$ & 0.063 & 6 & 0.019 & 15 \\
\hline & & & & $\mathrm{O}_{2}$ & 0.117 & 4 & 0.036 & 8 \\
\hline & & & & $\mathrm{O}_{3}$ & 0.242 & 2 & 0.074 & 4 \\
\hline & & & & $\mathrm{O}_{4}$ & 0.092 & 5 & 0.028 & 11 \\
\hline & & & & $\mathrm{O}_{5}$ & 0.341 & 1 & 0.104 & 3 \\
\hline & & & & $O_{6}$ & 0.145 & 3 & 0.044 & 7 \\
\hline \multirow[t]{6}{*}{ Threat } & 0.079 & 4 & 0.099 & & & & & \\
\hline & & & & $T_{1}$ & 0.077 & 5 & 0.006 & 18 \\
\hline & & & & $T_{2}$ & 0.129 & 3 & 0.010 & 17 \\
\hline & & & & $T_{3}$ & 0.122 & 4 & 0.010 & 17 \\
\hline & & & & $T_{4}$ & 0.387 & 1 & 0.031 & 9 \\
\hline & & & & $T_{5}$ & 0.285 & 2 & 0.023 & 13 \\
\hline
\end{tabular}




\section{Design e-PMS concept}

In order to design e-PMS concept for shipboard maintenance system, the weaknesses and threats factors of the current PMS must be handled by taking some solutions from the alternative maintenance systems. The proposed concept must tackle with vulnerabilities of the current PMS and must provide a modification for maintenance planning system. In light of the above, Table 10 shows proposed solutions to design an e-PMS concept.

Table 10 e-PMS concept solutions.

\begin{tabular}{cll}
\hline SWOT factor & Solution & Details of solution \\
\hline$W_{1}$ & Continuous monitoring & Provide to control system continuously. Thus, \\
& mechanism & if there would be any changes or fluctuating in \\
& & the system due to weak or poorly design, the \\
& & system can be corrected or replaced in \\
& & advance. So that, possible sudden operational \\
& failure can be avoided.
\end{tabular}

$W_{3} \quad$ Performance test mechanism Enable to conduct continuous empirical performance test for the system component. Thus, do not require periodic maintenance if the performance test result of system component found satisfactory level.

W5 Integration mechanism

Ensure to combine system in order to avoid time consuming by utilising trainings, demonstrations, presentations, applications, etc. of system users under supervision of the shore-based company experts.

T4 Extended database mechanism

Promote to record additional specific values, measures, and operational evidences regarding with shipboard systems. It will increase the crew motivation and awareness to monitor the equipment and systems from different viewpoints in routine watch keeping period

T5 $\quad$ Verification mechanism

Enable to verify work completion by creating alternative verification system. Thus, it would be understood whether relevant task is done or not. By conducting visual verification or regular interim shipboard inspection and shore-based audit can be alternative solution methods.

$T_{2} \quad$ Task rotation mechanism Provide system to relieve of uniformity by assigning crew into various tasks. Crew can able to participate miscellaneous task and improve their ability. Thus, crew may be aware of the task responsibility rather than stipulated in PMS periods. 
The e-PMS solution is depicted in Table 10. The concept can be adopted by maritime executives and responsible managers to modify the current PMS concept on-board ship. Taking the advantage of SWOT analysis, this study determines the critical points to be improved in PMS implementations on-board ships. Considering the weakness and threats in the system, the following mechanisms are adapted into the existing procedures of PMS: i) continuous monitoring mechanism, ii) Performance test mechanism, iii) Integration mechanism, iv) Extended database mechanism, v) Verification mechanism, vi) Task rotation mechanism. The integration of the mentioned mechanisms is leading to improve the maintenance operation planning, management, and monitoring under new concept so called as e-PMS. For instance, $\mathrm{W}_{1}$ (Not responding to sudden operational failure) should be upgraded by using a continuous monitoring mechanism to enable continuous system control. Thus, if any changes are observed in the performance of equipments or systems, it can be attached to current PMS in advance.

\section{Conclusion}

Poor maintenance planning is one of the core concerns in the maritime industry. It deals with the lack of a systematic approach towards technical ship management. It should be emphasized that existing ship maintenance systems (i.e. PMS) can be enhanced in light of the international regulations and technical standards. Therefore, an alternative shipboard maintenance system is required for maritime executives and responsible managers. This paper proposed a creative solution to design an enhanced planned maintenance system (e-PMS) for shipboard operations. To achieve this purpose, a hybrid approach (A'WOT) is employed. The technique basically combines the SWOT and AHP techniques. Whist the SWOT analysis is used to identify strengths, weaknesses, opportunities and threats of the current PMS on-board ships, the AHP technique quantifies its factors for evaluation.

In conclusion, the proposed e-PMS concept attempts to remedy gaps of the current PMS in shipboard operations. In the new concept, a set of creative modifications are suggested in accordance with the outcomes. To name the solutions; continuous monitoring mechanism, performance test mechanism, integration mechanism, extended database mechanism, verification mechanism, and task rotation mechanism are addressed. Hence, the e-PMS concept is developed by addressing the A'WOT. The ship management companies, shipowners, superintendents, classification societies and marine engineers take benefits of the findings and results of this paper since demonstration of e-PMS concept offers creative insight into maritime industry in safety management system improvement and intended to assure good functionality of ship's machinery. As the mentioned aspects are very relevant for shipping industry, the applied methodology and derivable contribute to maritime executives and responsible managers in ship engine department and safety department of ship management organizations. Within this context, the following subjects of the research can be highlighted;

- The limitations of the current PMS are revealed.

- The proposed e-PMS concept brings a solution for the vulnerabilities of current ship maintenance systems.

- The e-PMS concept offers alternative maintenance in safety management system improvement.

Since the aim of this paper is to conceptualise a methodologic approach for the e-PMS design, cost analysis has not been involved in. Further studies, in this context, may be extended with a cost effective analysis through the e-PMS concept. Furthermore, the alternative multi-criteria decision making model can be used instead of the AHP to compare the results of the research. 


\section{REFERENCES}

[1] Hubka V. and Eder W E. (1984). "Theory of Technical Systems”. Springer-Verlag London Limited. http://dx.doi.org/10.1007/978-3-662-10446-0.

[2] Cebi S., Celik M., Kahraman C. (2008). "Analyzing the needs of integrated maintenance management for shipboard systems". Journal of Aviation and Space Technology, Volume 3 (4): 17-24.

[3] Slavila C-A., Decreuse C., Ferney M. (2005). "Fuzzy Approach for Maintainability Evaluation in the Design Process". Concurrent Engineering: Research and Applications; 3(1): 61-73. http://dx.doi.org/10.1177/1063293x05059807.

[4] Chen L. and Cai J. (2003). "Using Vector Projection Method to evaluate maintainability of mechanical system in design review". Reliability Engineering and System Safety 81;147-154. http://dx.doi.org/10.1016/S0951$\underline{8320(03) 00075-9}$.

[5] Hao J P, Yu Y L., Xue Q. (2002). “A Maintainability Analysis Visualization System and its Development under the AutoCAD Environment”. Journal of Materials Processing Technology; 129(1-3):277-282. http://dx.doi.org/10.1016/S0924-0136(02)00665-9.

[6] Wani M F. and Gandhi O P. (2002). "Maintainability Design and Evaluation of Mechanical Systems based on Tribology”. Reliability Engineering \& System Safety; 77(2):181-188. http://dx.doi.org/10.1016/S0951$\underline{8320(02) 00032-7}$.

[7] Li K X. and Wonham J. (1999). "Who mans the world fleet? A follow-up to the BIMCO/ISF Manpower Survey". In: Maritime Policy and Management;26 (3):295-303. http://dx.doi.org/10.1080/030888399286907.

[8] Obando-Rojas B., Gardner B M., Naim M M. (1999). "A system dynamic analy sis of officer manpower in the merchant marine”. Maritime Policy and Management; 26(1):39-60. http://dx.doi.org/10.1080/030888399287050.

[9] Wang J. (2001). "The current status and future aspects in formal ship safety assessment”. Safety Science; 30:19-30. http://dx.doi.org/10.1080/030888399287050.

[10] Celik M. and Er I D. (2006). "Application Requirements of Catastrophe Theory in Maritime Transportation Industry". 3rd International Conference on Maritime Transport 16-19 May, Barcelona, Spain, pp: 879-887.

[11] Karahalios H. (2014). "The contribution of risk management in ship management: The case of ship collision." Safety Science 63: 104 - 114. http://dx.doi.org/10.1016/j.ssci.2013.11.004.

[12] Akyuz E. and Celik M.(2014). "A hybrid decision-making approach to measure effectiveness of safetv management system implementations on-board ship s". Safety Science 68: 169 - 179. http://dx.doi.org/10.1016/j.ssci.2014.04.003.

[13] Wang L., Chu J., Wu J. (2007). "Selection of optimum maintenance strategies based on a fuzzy analy tic hierarchy process". International Journal of Production Economics; 107(1):151-163. http://dx.doi.org/10.1016/j.ijpe.2006.08.005.

[14] Bevilacqua M. and Braglia M.(2000). "The analy tic hierarchv process an lied to maintenance strategv selection". Reliability Engineering and System Safety, 70:71-83. http://dx.doi.org/10.1016/S0951-8320(00)00047-8.

[15] Mechefske C K. and Wang Z. (2003). "Using fuzzy linguistics to select optimum maintenance and condition monitoring strategies". Mechanical Systems and Signal Processing; 17(2):305-316. http://dx.doi.org/10.1006/mssp.2001.1395.

[16] Labib A W. (2004). "A decision analy sis model for maintenance policv selection using a CMMS" Journal of Quality in Maintenance Engineering; 10(3):191-202. http://dx.doi.org/10.1108/13552510410553244.

[17] Pintelon L., Pinjala S K., Vereecke A. (2006). "Evaluating the effectiveness of maintenance strategies". Journal of Quality in Maintenance Engineering; 12(1):7-20. http://dx.doi.org/10.1108/13552510610654501.

[18] Zeng S W. (1997). "Discussion on maintenance strategy, policy and corresponding maintenance systems in manufacturing”. Reliability Engineering and System Safety; 55:151-162. http://dx.doi.org/10.1016/S0951$\underline{8320(96) 00004-X}$

[19] Waeyenbergh G.and Pintelon L. (2002). "Maintenance concept development: A case study". 12 ${ }^{\text {th }}$ International Working Seminar on Production Economics;1:347-359.

[20] Almeida A T. and Bohoris G A.(1995). "Decision theory in maintenance decision making”. Journal of Quality in Maintenance Engineering, 1(1):39-45. http://dx.doi.org/10.1108/13552519510083138.

[21] Bertolini M. and Bevilacqua M. (2006). "A combined goal programming-AHP approach to maintenance selection problem”. Reliability Engineering and System Safety 91: 839-848. http://dx.doi.org/10.1016/j.ress.2005.08.006.

[22] Mokashia A J., Wanga J., Vermarb A K. (2002). "A study of reliability-centered maintenance in maritime operations". Marine Policy; 26: 325-335. http://dx.doi.org/10.1016/S0308-597X(02)00014-3.

[23] Kotler P.(1988). “Marketing Management: Analysis, Planning, Implementation., and Control”. 6th edition, PrenticeHall International Edition.

[24] Wheelen T L. and Hunger J D. (1995). "Strategic Management and Business Policy", 5th edition. Addison Wesley, Reading, MA.

[25] Terrados J., Almonacid G., Hontoria L.(2007). "Regional energy planning through SWOT analy sis and strategic planning tools”. Renewable and Sustainable Energy Reviews; 11(6):1275-1287. http://dx.doi.org/10.1016/j.rser.2005.08.003. 
[26] Richardson J., McEwing G., Glasper E A. (2006). "Pre-registration children's and young people's nurse preparation". A SWOT analysis, Paediatric nursing; 18(10):34-37. http://dx.doi.org/10.7748/paed.18.10.34.s22.

[27] Paliwal R. (2006). "EIA practice in India and its evaluation using SWOT analysis". Environmental Impact Assessment Review; 26(5):492-510. http://dx.doi.org/10.1016/j.eiar.2006.01.004.

[28] Saaty T L. (1988)."Multicriteria Decision Making: The Analytic Hierarchy Process". RWS Publications, Pittsburg, PA.

[29] Akyuz E., Karahalios H., Celik M. (2015). “Assessment of the maritime labour convention compliance using balanced scorecard and analytic hierarchy process approach.” Maritime Policy \& Management, Vol. 42, No. 2: 145162. http://dx.doi.org/10.1080/03088839.2014.944239.

[30] Akyuz E. and Celik M. (2015). "A methodological extension to human reliabilitv analvsis for cargo tank cleaning operation on board chemical tanker ships". Safety Science 75: 146-155. http://dx.doi.org/10.1016/j.ssci.2015.02.008.

[31] Akyuz E. and Celik M.(2016). "A hybrid human error probability determination approach: The case of cargo loading operation in oil/chemical tanker ship". Journal of Loss Prevention in the Process Industries 43: 424 - 431. http://dx.doi.org/10.1016/j.jlp.2016.06.020.

[32] Vargas L.(1982). "Reciprocal matrices with random coefficients". Mathematical Modelling 3, 69-81. http://dx.doi.org/10.1016/0270-0255(82)90013-6.

[33] Akyuz E., Celik M., Cebi S. (2016). A phase of comprehensive research to determine marine-specific EPC values in human error assessment and reduction technique. Safety Science, 87: 63-75. http://dx.doi.org/10.1016/j.ssci.2016.03.013.

[34] Steuer R E. (2003). "Multiple criteria decision making combined with finance: A categorized bibliographic study". European Journal of Operational Research; 150(3):496-515. http://dx.doi.org/10.1016/S0377-2217(02)00774-9.

[35] Kurttila M., Pesonen M., Kangas J., Kajanus M. (2000). "Utilizing the analytical hierarchy process (AHP) in SWOT analysis - a hybrid method and its application to a forest-certification case". Forest Policy and Economics; 1(1):4152. http://dx.doi.org/10.1016/S1389-9341(99)00004-0.

[36] Stewart R A., Mohamed S., Daet R. (2002). "Strategic implementation of IT/IS proiects in construction: a case study". Automation in Construction; 11(6):681-694. http://dx.doi.org/10.1016/S0926-5805(02)00009-2.

[37] Ananda J and Herath G. (2003). "The use of Analytic Hierarchy Process to incorporate stakeholder preferences into regional forest planning". Forest Policy and Economics, 5:13-26. ttp://dx.doi.org/10.1016/S1389-9341(02)00043-6.

[38] Kangas J., Kurttila M., Kajanus M., Kangas A. (2003). "Evaluating the management strategies of a forestland estate-the S-O-S approach”. Journal of environmental management 69(4):349-358. http://dx.doi.org/10.1016/j.jenvman.2003.09.010.

[39] Kajanus M., Kangas J., Kurttila M. (2004). "The use of value focused thinking and the A'WOT hybrid method in tourism management”. Tourism Management; 25(4):499-506. http://dx.doi.org/10.1016/S0261-5177(03)00120-1.

[40] Shrestha R K., Alavalapati J R R., Kalmbacher R S.(2004). "Exploring the potential for silvopasture adoption in south-central Florida: an application of SWOT-AHP method". Agricultural Systems; 81(3):185-199. http://dx.doi.org/10.1016/j.agsy.2003.09.004.

[41] Chang H H. And Huang W C. (2006). "Application of a quantification SWOT analytical method". Mathematical and Computer Modelling; 43(1):158-169. http://dx.doi.org/10.1016/j.mcm.2005.08.016.

[42] IMO.(2002). "International Safety Management Code and Revised Guide lines on implementation of the ISM code by administrations". London: IMO.

[43] IACS. ( 2013). "International Association Of Classification Societies". IACS Members Listing.

[44] Kokangül A.Polat U. Dağsuyu C. (2017). "A new approximation for risk assessment using the AHP and Fine Kinney methodologies". Safety Science 91: 24 - 32. http://dx.doi.org/10.1016/j.ssci.2016.07.015.

Dweiri F., Kumar S., Khan S A., Jain V. (2016). "Designing an integrated AHP based decision support system for supv lier selection in automotive industrv." Expert Systems With Applications 62: 273 - 283. http://dx.doi.org/10.1016/j.eswa.2016.06.030.

Submitted: 02.03 .2016

Accepted: 11.10 .2016
Emre Akyuz, emreakyuz82@gmail.com

Department of Maritime Management, Bursa Technical University,

Yildirim, 16330, Bursa, Turkey

Metin Celik

Department of Marine Engineering, Istanbul Technical University, Tuzla 34940, Istanbul, Turkey 